\title{
ANALISIS ASPEK PERPAJAKAN ATAS JASA SEWA KANTOR VIRTUAL
}

\section{Muhammad Pranasa Aranta Syaiful Dinar}

Direktorat Jenderal Pajak, Indonesia. Email: pranasa.dinar@gmail.com

\section{ABSTRACT}

This study aims to analyze the taxation aspects of virtual office rental services. With the issuance of PMK-147/PMK.03/2017, it is hoped that taxpayers will find it easier to carry out their tax obligations related to virtual office rental services. Using a descriptive study approach, this qualitative research is expected to describe and understand the phenomenon of virtual office rental services with a deep focus. The study results indicate that there are still differences in the definition of a virtual office between taxpayers and the DGT, giving rise to the practice of imposing different virtual office rental taxes between taxpayers. Income from virtual office rental services is subject to Income Tax Article 4 paragraph (2), Income Tax Article 23, and Income Tax Article 4 paragraph (1). Thus, regulatory certainty is needed on the taxation of virtual office rental services.

Keywords: taxation, virtual office, rental services

\section{ABSTRAK}

Penelitian ini bertujuan untuk menganalisis aspek-aspek perpajakan atas jasa sewa kantor virtual. Dengan diterbitkannya PMK-147/PMK.03/2017, diharapkan wajib pajak lebih mudah dalam menjalankan kewajiban perpajakan terkait jasa sewa kantor virtual. Menggunakan pendekatan studi deskriptif, penelitian kualitatif ini diharapkan mampu mendeskripsikan dan memahami fenomena jasa sewa kantor virtual dengan fokus yang mendalam. Hasil penelitian menunjukkan bahwa masih terdapat perbedaan definisi kantor virtual antara Wajib Pajak dengan DJP sehingga menimbulkan praktik pengenaan pajak jasa sewa kantor virtual yang berbeda antar wajib pajak. Penghasilan dari jasa sewa kantor virtual ada yang dikenakan PPhPasal 4 ayat (2), PPh Pasal 23 dan PPh Pasal 4 ayat (1). Dengan demikian diperlukan kepastian regulasi Pasal 4 ayat (2), PPh Pasal 23 dan PPh Pasal 4 ayat (1). Dengan demikian diperlukan kepastian regulasi atas perpajakan jasa sewa kantor virtual.

Kata kunci: pajak, kantor virtual, jasa sewa 


\section{PENDAHULUAN}

\subsection{Latar Belakang}

Perkembangan teknologi informasi sejalan dengan perkembangan di dunia usaha. Proses bisnis yang dulunya dilakukan dengan tatap muka sekarang dapat dilakukan melalui media internet (Utami, 2010). Berdasarkan data dari Internet World Stats (2018) per Desember 2017, sebanyak $53,7 \%$ penduduk Indonesia merupakan pengguna internet, atau sekitar 143,26 juta orang. Internet menjadi media promosi yang paling diminati. Transaksi bisnis melalui internet ini dikenal sebagai perdagangan elektronik (e-commerce).

\section{E-commerce membuat proses} penjualan dan pembelian lebih mudah. Namun lambat laun perusahaan memerlukan lokasi usaha di dunia nyata. Aspek legalitas dan prasarana merupakan alasan utama memilih lokasi usaha. Hanya saja, jumlah perusahaan yang sudah berdiri tidak sebanding dengan lokasi usaha yang disediakan. Menyikapi hal tersebut, saat ini sudah ada konsep kantor virtual (virtual office) sebagai solusi dalam mengatasi permasalahan kebutuhan perkantoran. Kantor virtual merupakan kantor dimana penyewa hanya memiliki alamat dari kantor tersebut tanpa memiliki ruangan secara fisik.

Konsep kantor virtual sebenarnya sudah ada sejak awal tahun 1960-an. IBM menciptakan istilah word processing yang merupakan awal dari konsep Office
Automation (OA). OA merupakan sistem informasi elektronik baik formal maupun informal untuk mendukung proses informasi (McLeod \& Schell, 2008, p. 40-41). Hal ini menjadi dasar terciptanya konsep kantor virtual. Kantor virtual merupakan pelaksanaan dari kegiatan kantor secara independen tanpa harus melibatkan kantor fisik. Kantor virtual mulai dikenal di Indonesia sekitar tahun 2010-an sejak perusahaan rintisan mulai banyak bermunculan sebagai industri kreatif berbasis digital.

Perusahaan rintisan yang mulai banyak bermunculan berarti jumlah Wajib Pajak (WP) Badan juga bertambah di Indonesia. Direktorat Jenderal Pajak (DJP) tentu melihat fenomena ini sebagai sarana untuk menghimpun dana. Namun pendaftaran WP badan yang memiliki kantor virtual mengalami kendala saat mengajukan pengukuhan Pengusaha Kena Pajak (PKP). Permohonan pengukuhan PKP sebelumnya diatur melalui PMK Nomor 182/PMK.03/2015 tentang Tata Cara Pendaftaran Nomor Pokok Wajib Pajak, Pengukuhan Pengusaha Kena Pajak, Penghapusan Nomor Pokok Wajib Pajak, dan Pencabutan Pengukuhan Pengusaha Kena Pajak. Aturan ini belum memperbolehkan kantor virtual sebagai tempat pengukuhan PKP.

Dikarenakan peraturan yang ada belum mengakomodasi kantor virtual sebagai tempat pengukuhan PKP, Kantor Pelayanan Pajak (KPP) Pratama Jakarta Tebet membuat 
kebijakan tambahan agar WP Badan yang menggunakan kantor virtual dapat dikukuhkan sebagai PKP. Kebijakan yang dilakukan ialah melampirkan dokumen tambahan pada saat pengukuhan PKP. Dokumen tambahan tersebut berupa alamat dan foto ruangan kerja lainnya, seperti rumah direksi, workshop, dan koordinat alamatnya. Kebijakan antara KPP satu dengan KPP lain belum tentu sama. Perbedaan kebijakan ini memungkinkan terjadinya perlakuan yang tidak sama antara KPP satu dengan KPP yang lain. Hal ini membuat proses administrasi perpajakan tidak bisa memberikan kepastian kepada WP.

Pada tanggal 18 November 2016, KPP Pratama Jakarta Setiabudi Tiga menyampaikan surat dengan nomor S37173/WPJ.30/KP.03/2016 kepada Direktorat Peraturan Perpajakan I tentang Permohonan Penegasan Permohonan Pengukuhan Pengusaha Kena Pajak yang Menggunakan Virtual Office. Hasil dari pembahasan tersebut adalah Kasubdit Peraturan PPN Perdagangan, Jasa, dan Pajak Tidak Langsung Lainnya (PTLL) merekomendasikan kepada Kasubdit Peraturan Ketentuan Umum dan Tata Cara Perpajakan dan Penagihan Pajak dengan Surat Paksa (KUP dan PPSP) untuk segera melakukan perubahan regulasi terkait dengan masalah sebagaimana dimaksud. Hal ini disebabkan persyaratan pengukuran PKP yang ada saat ini belum mempertimbangkan perkembangan yang terjadi dalam kaitannya dengan kantor virtual.

Pada tanggal 1 November 2017, berlaku Peraturan Menteri Keuangan Nomor PMK147/PMK.03/2017 tentang Tata Cara Pendaftaran Wajib Pajak dan Penghapusan Nomor Pokok Wajib Pajak serta Pengukuran dan Pencabutan Pengukuhan Pengusaha Kena Pajak. Peraturan ini memberikan definisi mengenai kantor virtual dan persyaratan yang dibutuhkan dalam permohonan PKP. PMK-147/PMK.03/2017 muncul sebagai jawaban atas permasalahan permohonan pengukuhan PKP. Namun, peraturan ini masih bersifat administratif. Peraturan ini hanya menjelaskan dokumen persyaratan dan definisi kantor virtual saja.

Pada praktiknya, PMK-147/PMK.03/2017 hanya mengatur mengenai aspek Pajak Pertambahan Nilai terkait dengan pengukuhan PKP. Selain itu, aturan teknis aspek Pajak Penghasilan seperti pemotongan dan pemungutan pajak atas sewa kantor virtual dan teknis pembebanan atas biaya yang dikeluarkan penyedia jasa kantor virtual belum diatur lebih lanjut. Berdasarkan Pasal 4 ayat (1) huruf a Undang Undang Nomor 36 Tahun 2008 tentang Pajak Penghasilan (UU PPh), atas penghasilan jasa sewa-menyewa yang diterima oleh virtual office dapat dikategorikan sebagai objek pajak. Namun UU PPh tidak secara eksplisit mendefinisikan virtual office. Dalam Pasal 1 ayat 
Peraturan Menteri Keuangan Nomor 141/PMK.03/2015, jasa sewa virtual office belum terdefinisikan sebagai jasa lain yang dimaksud dalam pasal 23 ayat (1) huruf c angka 2 UU PPh. Hal-hal tersebut bisa menimbulkan ketidakpastian hukum dari segi aspek perpajakan. Disisi lain belum ada penelitian yang secara khusus membahas aspek perpajakan atas kantor virtual. Pada tahun 2014, Cahyadi melakukan tinjauan yuridis mengenai perjanjian sewa-menyewa virtual office dan dampak penggunaan alamat virtual office sebagai domisili pada perjanjian. Kurangnya penelitian mengenai aspek perpajakan kantor virtual dan belum adanya peraturan perpajakan yang secara tegas mengatur kantor virtual dapat menyebabkan perbedaan pandangan terkait pengenaan pajak kantor virtual. Oleh karena itu, penting dilakukan penelitian guna merumuskan aspek perpajakan terkait jasa sewa kantor virtual.

\subsection{Rumusan Masalah}

Berdasarkan latar belakang penelitian yang telah dipaparkan sebelumnya, masalah dalam penelitian ini dapat diidentifikasi sebagai berikut:

1. Bagaimana pengenaan pajak terhadap penghasilan atas jasa sewa kantor virtual?

2. Bagaimana perlakuan pembebanan biaya atas layanan pendukung kantor yang dikeluarkan oleh penyedia jasa sewa kantor virtual?

\subsection{Manfaat Penelitian}

Penelitian ini diharapkan dapat memberikan manfaat bagi Direktorat Jenderal Pajak sebagai bahan pertimbangan dan input dalam menentukan dan merumuskan kebijakan pengenaan pajak kantor virtual.

\section{LANDASAN TEORI}

\subsection{Landasan Teori}

\subsubsection{Konsep Domisili}

Dalam Kitab Undang-undang Hukum Perdata (KUHPerdata), domisili adalah tempat kedudukan resmi yang dapat berupa tempat tinggal, rumah, kantor, atau kota yang mempunyai hak dan kewajiban di mata hukum. Tempat kedudukan menurut Pasal 2 ayat (6) Undang-Undang Nomor 36 Tahun 2008 tentang perubahan keempat Undang-Undang Nomor 7 Tahun 1983 tentang Pajak Penghasilan (UU PPh) ditetapkan oleh Direktur Jenderal Pajak menurut keadaan yang sebenarnya.

Penentuan tempat kedudukan baik untuk orang pribadi maupun badan merupakan hal yang penting dalam konteks perpajakan untuk menetapkan KPP mana yang mempunyai yurisdiksi pemajakan atas penghasilan yang diterima atau diperoleh orang pribadi maupun badan tersebut. Sebelum adanya PMK-147/PMK.03/2017, penggunaan alamat kantor virtual untuk pengukuhan PKP tidak diperbolehkan 
karena bertentangan dengan Pasal 9 Peraturan Menteri Keuangan Nomor 146/PMK.03/2012 tentang Tata Cara Verifikasi.

Pengukuhan PKP menggunakan alamat kantor virtual menurut PMK146/PMK.03/2012 tidak diperbolehkan karena tempat kedudukan kantor virtual tidak dapat dianggap sebagai tempat kegiatan usaha menurut keadaan yang sebenarnya. Namun, setelah adanya PMK147/PMK.03/2017, penggunaan alamat kantor virtual diperbolehkan dengan tambahan persyaratan. Persyaratan tersebut tercantum dalam Pasal 46 ayat (2) antara lain pengusaha pengguna jasa Kantor Virtual dimaksud memiliki izin usaha dan terpenuhinya kondisi pengelola kantor virtual yaitu telah dikukuhkan sebagai PKP, menyediakan ruang fisik untuk tempat kegiataan usaha bagi Pengusaha yang akan dikukuhkan sebagai PKP, serta secara nyata melakukan kegiatan layanan pendukung kantor.

\subsubsection{Konsep Sewa-Menyewa}

Perjanjian sewa-menyewa merupakan suatu perjanjian consensual, yang artinya perjanjian tersebut sudah sah dan mengikat pada detik tercapainya kata sepakat mengenai unsur-unsur pokoknya, yaitu barang dan harga. Pengertian perjanjian sewa-menyewa menurut Pasal 1548 KUHPerdata adalah: "Suatu perjanjian, dengan mana pihak yang satu mengikatkan dirinya untuk memberikan kepada pihak yang lainnya kenikmatan dari suatu barang, selama suatu waktu tertentu dan dengan pembayaran sesuatu harga, yang oleh pihak tersebut belakangan itu disanggupi pembayarannya."

Dalam aspek perpajakan, objek pajak atas sewa adalah sewa sehubungan dengan penggunaan harta sebagaimana dimaksud dalam Pasal 23 ayat (1) huruf c UU PPh dan persewaan tanah dan/atau bangunan sebagaimana dimaksud dalam Pasal 4 ayat (2) UU PPh. Keduanya memiliki perbedaan tarif pajak. Atas penghasilan dari sewa sehubungan dengan penggunaan harta dipotong 2\% (dua persen) dari jumlah bruto dan bersifat tidak final, sedangkan atas penghasilan dari persewaan tanah dan/atau bangunan dipotong 10\% (sepuluh persen) dan bersifat final.

\subsubsection{Konsep Konser Virtual}

Habib dan Cornford (2014, p. 1) mendefinisikan kantor virtual sebagai tempat ruang kerja maya dimana secara geografis terpisah dari ruang kerja utamanya, namun terhubung lewat teknologi telekomunikasi maya. Maksud dari definisi tersebut adalah konsep kantor yang tidak memiliki wujud fisik dimana kegiatan berkantor dilakukan dan terhubung lewat teknologi informasi dunia maya.

Pada tahun 1964, IBM memperkenalkan produk ciptaannya yang disebut Magnetic Tape/Selectric Typewriter yang menjadi awal dari sebuah otomatisasi kantor (Office Automation). Dalam praktiknya, konsep kantor virtual tidak lagi mengarah kepada OA namun lebih kepada penggunaan 
alamat kantor untuk dijadikan alamat bisnis perusahaan. Locsin (2014) mendefinisikan kantor virtual menjadi sebuah bisnis dimana bisnis tersebut menawarkan penyewaan kantor yang dilengkapi dengan jasa resepsionis, ruang rapat, dan nomor telepon cukup dengan membayar sewa perbulan.

Dalam aspek perpajakan, definisi kantor virtual menurut Pasal 1 angka 22 Peraturan Menteri Keuangan Nomor 147/PMK.03/2017 tentang Tata Cara Pendaftaran Wajib Pajak dan Penghapusan Nomor Pokok Wajib Pajak serta Pengukuran dan Pencabutan Pengukuhan Pengusaha Kena Pajak adalah sebagai berikut:"Kantor Virtual (virtual office) atau Kantor Bersama (co-working space), yang selanjutnya disebut Kantor Virtual, adalah suatu kantor yang memiliki ruangan fisik dan dilengkapi dengan layanan pendukung kantor yang disediakan oleh pengelola Kantor Virtual untuk dapat digunakan sebagai tempat kedudukan, tempat kegiatan usaha, atau korespondensi secara bersama-sama oleh 2 (dua) atau lebih Pengusaha yang atas pemanfaatan kantor dimaksud terdapat pembayaran dalam bentuk apapun, tidak termasuk jasa persewaan gedung dan jasa persewaan kantor (serviced office)."

Kantor virtual dalam perpajakan harus berupa ruangan fisik. Hal ini berbeda dengan OA yang mengandalkan jaringan komputer sebagai sarana pertukaran informasi. Penyedia jasa harus memiliki ruangan dan dilengkapi dengan layanan pendukung kantor. Kantor virtual berupa bangunan fisik mendapatkan perlakuan yang sama dengan bangunan pada umumnya. Selain mengeluarkan biaya untuk menyediakan layanan pendukung kantor, penyedia jasa kantor virtual juga harus mengeluarkan biaya perawatan untuk memelihara bangunan.

\subsubsection{Konsep Biaya}

Menurut Mulyadi (2010, p. 8), biaya dalam arti luas adalah pengorbanan sumber ekonomi, yang diukur dalam satuan uang, yang telah terjadi atau yang kemungkinan akan terjadi untuk tujuan tertentu. Dalam aspek perpajakan, biaya berfungsi sebagai pengurang atas penghasilan bruto untuk mendapatkan besaran Penghasilan Kena Pajak. Biaya yang dapat menjadi pengurang berdasarkan Pasal 6 ayat (1) UU PPh.

\subsection{Hasil Penelitian Sebelumnya}

Penelitian mengenai aspek perpajakan pada umumnya telah banyak diteliti. Akan tetapi, khusus aspek perpajakan kantor virtual belum banyak dilakukan. Namun, terdapat penelitian yang cukup relevan. Ciptadi (2014) dalam penelitiannya yang berjudul "Tinjauan Yuridis Mengenai Perjanjian SewaMenyewa Virtual Office dan Dampak Penggunaan Alamat Virtual Office sebagai Domisili pada Perjanjian" menjadikan perjanjian sewa-menyewa berbentuk virtual office sebagai obyek penelitian. Hasil penelitian menunjukkan bahwa alamat kantor (konvensional) dapat dikategorisasikan sebagai benda/properti. Alamat konvensional dapat dipersamakan dengan nama domain dimana keduanya 
memiliki kemiripan yaitu tidak berwujud dan merupakan suatu identitas atau penunjuk suatu lokasi. Selain itu, perjanjian sewamenyewa alamat virtual office tidak dapat dianggap sebagai perjanjian sewamenyewa yang diatur dalam KUHPerdata sebab perjanjian sewa-menyewa alamat tidak memenuhi unsur esensialia dari sebuah perjanjian.

\subsection{Kerangka Penelitian}

Berdasarkan penjelasan mengenai latar belakang dan landasan teori, kerangka pemikiran yang dikembangkan penulis dalam penelitian ini sebagaimana dalam gambar di bawah yang memperlihatkan alur pikir yang dimulai dari permasalahan sampai dengan analisis dan pembahasan untuk kemudian diuraikan dalam penelitian. Pengumpulan data dilakukan melalui wawancara dan studi literatur kemudian dianalisis untuk ditarik simpulan dan memberikan rekomendasi jika diperlukan.

\subsection{Alasan Menggunakan Metode Kualitatif}

Jenis penelitian yang digunakan adalah penelitian kualitatif dengan pendekatan studi deskriptif. Tujuan penelitian kualitatif pada umumnya mencakup informasi tentang fenomena utama yang dieksplorasi dalam penelitian, partisipan penelitian dan lokasi penelitian (Crosswell, 2016, p. 164). Pendekatan kualitatif menjadi model yang tepat untuk menyelesaikan masalah penelitian karena model kualitatif mendeskripsikan dan memahami suatu permasalahan dengan fokus yang mendalam.

\subsection{Objek Penelitian}

Objek penelitian difokuskan kepada WP yang memiliki kantor virtual yang berkedudukan hukum di Indonesia, pemotongan dan pemungutan jasa kantor virtual, dan mekanisme perlakuan biaya

\section{METODOLOGI PENELITIAN}

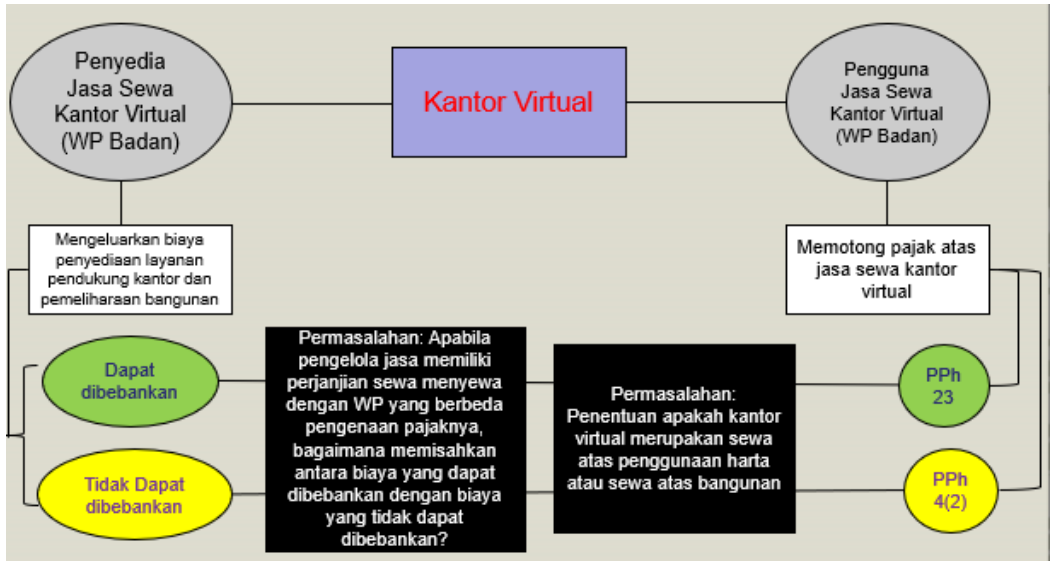

Gambar 1 Kerangka Penelitian

Sumber: Diolah Penulis 
yang dikeluarkan dalam rangka memperoleh, menagih, dan memelihara penghasilan.

\subsection{Sumber Data Penelitian dan Narasumber}

Penelitian ini menggunakan data primer dan data sekunder. Data primer diperoleh melalui wawancara mendalam (in-depth interview) kepada orang-orang yang dipandang tahu dengan situasi sosial terkait penelitian. Penentuan sumber data pada orang yang diwawancarai dilakukan secara purposive, yaitu dipilih dengan pertimbangan dan tujuan tertentu (Sugiyono, 2016, p. 216). Narasumber penelitian ini disajikan dalam Lampiran Tabel 1.

Data sekunder yang digunakan dalam penelitian ini merupakan data yang diperoleh dari sumber yang relevan dengan objek penelitian, di antaranya diperoleh dari penelitian kepustakaan berupa jurnal-jurnal ilmiah yang berkaitan dengan penelitian.

\subsection{Teknik Pengumpulan Data}

Peneliti menggunakan beberapa teknik pengumpulan data wawancara mendalam (in depth interview) dan dokumentasi.

\subsection{Metode Pengolahan Data}

Analisis data pada penelitian ini bersifat induktif, yaitu berdasarkan data yang diperoleh. Adapun rincian proses analisis data yang penulis lakukan adalah sesuai dengan aktivitas analisis data kualitatif menurut Miles dan Huberman sebagaimana dikutip oleh Sugiyono (2016, p. 430-438), yaitu sebagai berikut:

1. Reduksi data (data reduction);

Reduksi data dilakukan dengan cara melakukan coding atas hasil wawancara.

2. Penyajian data (data display);

3. Penarikan kesimpulan (conclusion drawing).

\subsection{Penguji Keabsahan Data}

Metode penelitian kualitatif menggunakan istilah yang berbeda dengan penelitian kuantitatif. Metode kualitatif menggunakan istilah credibility (validitas internal), transferability (validitas eksternal), dependability (reliabilitas), dan confirmability (obyektivitas) dalam pengujian keabsahan data (Sugiyono, 2016, p. 269-270).

\section{HASIL DAN PEMBAHASAN \\ 4.1 Pengenaan Pajak Terhadap Penghasilan atas Jasa Sewa Kantor Virtual}

4.1.1 Perbedaan Definisi Virtual Office

Dalam PMK-147/PMK.03/2017 terdapat istilah jasa persewaan kantor (virtual office). Kantor virtual menurut definisi PMK147/PMK.03/2017 mengharuskan adanya ruangan fisik. Dony Katra Lubis menjelaskan pengertian kantor virtual di berbagai negara ada yang mengharuskan adanya ruangan masing-masing dan ada juga yang menganggap tidak perlu ada ruangan. Kesimpulan yang diambil oleh DJP adalah 
memperbolehkan kantor virtual sebagai tempat kedudukan untuk pendaftaran Nomor Pokok Wajib Pajak (NPWP) dan pengukuhan PKP asalkan sesuai dengan aturan perpajakan di Indonesia. Aturan tersebut mengharuskan adanya ruangan fisik bagi kantor virtual. Hal ini sejalan dengan Nathalie Ardjani yang menyatakan bahwa label nama menunjukkan adanya tenant yang menyewa di tempat tersebut. Penentuan kantor virtual juga harus dilihat dari kontrak perjanjian sewanya. David Hamzah Damian menjelaskan bahwa dengan melihat kontrak, hak dan kewajiban pihak penyewa dan yang menyewakan dapat terlihat. Selain itu, substansi transaksinya dapat dibandingkan dengan transaksi yang sebenarnya.

Berdasarkan hasil wawancara, penulis menyimpulkan bahwa terdapat perbedaan definisi antara kantor virtual menurut penyedia jasa sewa kantor virtual selaku WP dan DJP selaku pembuat peraturan perpajakan. Definisi jasa sewa kantor virtual menurut penyedia jasa sewa kantor virtual berupa sewa alamat bisnis yang diberikan beberapa fasilitas, salah satunya adalah fasilitas ruangan rapat. Namun, definisi kantor virtual menurut DJP adalah suatu kantor yang memiliki ruangan fisik dan dilengkapi dengan layanan pendukung kantor. Kondisi ideal yang diharapkan adalah ruangan fisik tersebut tersedia bagi setiap pengguna jasa (space for each client).

Pada praktiknya, ruangan fisik yang disediakan oleh penyedia jasa sewa kantor virtual hanyalah ruangan rapat yang diberikan jatah beberapa jam tiap bulannya.
Aturan PMK-147/PMK.03/2017 memberikan toleransi atas kondisi tersebut sehingga konteks ruangan fisik tidak diberikan batasan secara bentuk dan ukuran. Konsekuensinya, jasa sewa kantor virtual yang diperbolehkan oleh DJP adalah jasa sewa kantor virtual yang memiliki fasilitas ruangan rapat sehingga jasa sewa kantor virtual yang hanya berupa alamat bisnis tidak termasuk dalam definisi kantor virtual. Alasan DJP mengharuskan adanya ruangan fisik adalah sebagai sarana identifikasi tempat kegiatan usaha dalam pengukuhan PKP dan sebagai cara DJP menjangkau WP dalam administrasi perpajakan.

\subsubsection{Objek Jasa Sewa Kantor Virtual}

Setelah mengetahui definisi kantor virtual, langkah selanjutnya adalah mengetahui substansi transaksi yang sebenarnya atas jasa sewa kantor virtual. Objek perjanjian sewa-menyewa menurut Pasal 1548 KUHPerdata adalah barang. Nathalie Ardjani, Erin Supriyanti, dan Regal Gautama sebagai pihak yang mewakili penyedia jasa sewa kantor virtual menyatakan bahwa jasa sewa kantor virtual merupakan sewa alamat. Alamat yang dimaksud oleh penyedia jasa sewa kantor virtual adalah alamat yang dapat digunakan oleh pengguna jasa sewa kantor virtual sebagai alamat kegiatan usaha. Bila dilihat dari hukum perdata, alamat tidak dapat dikategorikan sebagai barang karena tidak konkrit dan tidak berwujud sehingga tidak bisa dijadikan objek sewa-menyewa. Dengan kata lain, 
unsur esensialia dari perjanjian sewamenyewa kantor virtual tidak terpenuhi.

Ety Rahmawati berpendapat bahwa meski pengguna jasa sewa kantor virtual hanya diberikan kubikel namun bila syarat itu memenuhi tempat untuk setiap klien dapat dikatakan sebagai bagian dari bangunan. Oleh karena itu, atas objek jasa sewa kantor virtual dianggap sebagai sewa tanah dan bangunan. Rika Hafidha Rahmasopha juga menganggap bahwa istilah jasa sewa kantor virtual masih dalam konsep sewa tanah dan bangunan.

Berdasarkan uraian di atas, penulis menyimpulkan perjanjian sewa-menyewa kantor virtual tetap sah di mata hukum karena sewa-menyewa kantor virtual tidak bertentangan dengan peraturan perundang-undangan. Adapun yang menjadi objek sewa sebenarnya atas jasa sewa kantor virtual adalah alamat untuk kegiatan usaha. Alamat kegiatan usaha dapat dimaknai sebagai tempat korespondensi. Alamat kegiatan usaha dari sudut pandang perpajakan diterjemahkan sebagai tempat kedudukan dalam rangka pendaftaran NPWP dan pengukuhan PKP. Selain itu, pandangan bahwa adanya ruangan fisik di dalam kantor virtual berupa ruangan rapat dapat dikategorikan sebagai bagian dari sewa tanah dan bangunan. Objek sewa dapat diketahui dari perjanjian sewa-menyewa antara penyedia jasa sewa kantor virtual dengan pengguna jasa sewa kantor virtual. Oleh karena itu, perlu dilihat substansi transaksi yang sebenarnya melalui perjanjian tersebut.
4.1.3 Pengukuhan Pengusaha Kena Pajak bagi Wajib Pajak yang memiliki Kantor Virtual

Salah satu alasan dibentuknya PMK147/PMK.03/2017 adalah permasalahan pengukuhan PKP bagi WP yang bertempat di kantor virtual tidak memenuhi persyaratan verifikasi menurut PMK146/PMK.03/2012. Alamat menjadi sarana yang penting saat mendaftarkan diri untuk mendapatkan NPWP maupun saat mengukuhkan sebagai PKP. Dengan diterbitkannya PMK-147/PMK.03/2017, WP yang menggunakan kantor virtual dapat menggunakan alamat virtual office saat mendaftarkan diri sebagai PKP. Pasal 45 ayat (2) dan pasal 46 ayat (2) PMK147/PMK.03/2017 menyatakan bahwa kriteria kantor virtual sebagai tempat PKP dikukuhkan harus memenuhi kriteria sebagai berikut:

1. Terpenuhi kondisi pengelola kantor virtual sebagai berikut:

a. Telah dikukuhkan sebagai PKP

b. Menyediakan ruangan fisik untuk tempat kegiatan usaha bagi pengusaha yang akan dikukuhkan sebagai PKP; dan

c. Secara nyata melakukan kegiatan layanan pendukung kantor

2. Pengusaha pengguna kantor virtual memiliki izin usaha atau dokumen sejenis lainnya yang diterbitkan oleh pejabat atau instansi yang berwenang.

Bagi penyedia jasa sewa kantor virtual, status PKP yang dimiliki dapat menjadi nilai 
tambah dalam melakukan kegiatan usahanya karena dapat melakukan pengkreditan atas transaksi yang dikenakan PPN. Dari sudut pandang regulator, Andik Tri Sulistyono menyatakan bahwa tujuan penyedia jasa sewa kantor virtual dikukuhkan sebagai PKP adalah sebagai sarana pengendalian DJP dalam mengawasi siapa saja WP yang memiliki kantor virtual di sana sehingga tidak ada potensi PPN yang hilang.

\subsubsection{Pengenaan Pajak Penghasilan atas Jasa Sewa Kantor Virtual}

Penghasilan dari jasa sewa kantor virtual merupakan objek pajak sehingga dikenakan pajak penghasilan. Penyedia jasa sewa kantor virtual umumnya berbentuk badan hukum. Penyedia jasa sewa kantor virtual harus mendaftarkan diri agar diberikan NPWP karena sudah memenuhi persyaratan subjektif dan objektif.

Keputusan Direktur Jenderal Pajak Nomor KEP-321/PJ/2012 tidak menyediakan Klasifikasi Lapangan Usaha (KLU) untuk penyedia jasa sewa kantor virtual secara jelas sehingga baik petugas help desk maupun petugas TPT Seksi Pelayanan KPP menentukan KLU penyedia jasa sewa kantor virtual berdasarkan penilaian subjektif. Rika Hafidha Rahmasopha menyatakan bahwa WP yang memiliki kode KLU 68110 "Real Estat yang Dimiliki Sendiri atau Disewa" dapat menjadi indikasi sebagai penyedia jasa sewa kantor virtual.

Pada bagian sebelumnya, telah dijelaskan bahwa objek sebenarnya atas jasa sewa kantor virtual adalah alamat untuk kegiatan usaha. Pengenaan pajak penghasilan dapat diketahui dengan menafsirkan objek tersebut terhadap objek pajak menurut Pasal 4 UU PPh. Namun pada praktiknya terdapat berbagai macam pengenaan pajak penghasilan atas jasa sewa kantor virtual.

Pengenaan pajak penghasilan yang terjadi selama ini hanya berdasarkan praktik yang sudah berjalan sebelumnya. Bahkan, ada penyedia jasa sewa kantor virtual yang belum dikukuhkan sebagai PKP sejak diberlakukannya PMK-147/PMK.03/2017. Selain itu, adanya perbedaan perlakuan pengenaan pajak penghasilan antara penyedia jasa sewa kantor virtual satu dengan yang lain menunjukkan masih adanya ketidakpastian hukum dalam pengenaan pajak penghasilan atas jasa sewa kantor virtual.

Kantor virtual yang ada dalam definisi PMK-147/PMK.03/2017 mengharuskan adanya ruangan fisik. Konteks ruangan fisik yang memberikan hak eksklusivitas dianggap merupakan bagian dari sewa tanah dan bangunan sehingga dikenakan PPh Pasal 4 ayat 2. Namun, Andik Tri Sulistyono menjelaskan layanan pendukung kantor menjadi indikator bahwa penyedia jasa sewa kantor virtual terlibat dalam kegiatan manajemen pengguna jasa sewa kantor virtual. Meskipun menyediakan ruangan rapat, kenyataannya pengguna jasa sewa kantor virtual tidak memiliki kendali atas ruangan tersebut. Hal ini menunjukkan adanya keterlibatan penyedia jasa sewa kantor virtual. Dengan kata lain, 
jasa sewa kantor virtual termasuk dalam jasa manajemen menurut Pasal 23 UU PPh.

Berbeda dengan pendapat di uraian sebelumnya, David Hamzah Damian berpendapat bahwa apabila PPh Pasal 23 bersifat positive list. Oleh karena itu, jasa sewa kantor virtual tidak bisa dikenakan PPh Pasal 23 karena tidak ada definisi atas jasa sewa kantor virtual yang jelas di dalamnya dan juga tidak ada dalam jenis jasa lain yang diatur di PMK Nomor 141/PMK.03/2015. David Hamzah Damian juga menyatakan bahwa jasa sewa kantor virtual tidak memenuhi kriteria sewa tanah dan bangunan. Dengan demikian, jasa sewa kantor virtual tidak dikenakan PPh Pasal 23 dan PPh Pasal 4 ayat 2. Penghasilan atas jasa sewa kantor virtual justru tidak dilakukan pemotongan dan pemungutan dan tetap menjadi objek penghasilan sesuai dengan Pasal 4 ayat 1 UU PPh.

Hidayat Putra Jaya berpendapat bahwa secara faktual jasa sewa kantor virtual lebih cenderung kepada jasa. Akan tetapi, definisi jasa manajemen dirasa terlalu luas bagi jasa sewa kantor virtual. Oleh karena itu, jasa sewa kantor virtual dimasukkan dalam kategori sewa tanah dan bangunan dan dikenakan PPh Pasal 4 ayat 2. Hal senada juga disampaikan oleh Arief Sultony bahwa penyedia jasa sewa kantor virtual punya ruangan untuk disewakan atau untuk dikelola. Konteks ruangan fisik yang memberikan hak eksklusivitas dianggap merupakan bagian dari sewa tanah dan bangunan sehingga dikenakan PPh Pasal 4 ayat 2 .

Pendapat berbeda datang dari Maulia Ghita. Dia menjelaskan bahwa keberadaan kantor virtual sebagai alamat kegiatan usaha seolah-olah menyatakan keberadaan WP. Di sisi lain, ruangan rapat disediakan tidak secara terus-menerus oleh penyedia jasa sewa kantor virtual. Apabila dalam perjanjian sewa kantor virtual dapat dipisahkan bagian-bagian yang merupakan ruangan rapat dan jasa, ruangan fisik tersebut dapat dikenakan PPh Pasal 4 ayat 2

Tabel 1 Pendapat Narasumber atas Pengenaan Pajak Virtual Office

Sumber: Data diolah

\begin{tabular}{|l|l|}
\hline \multicolumn{1}{|c|}{ Narasumber } & \multicolumn{1}{|c|}{ Pendapat atas Pengenaan Pajak Virtual Office } \\
\hline Nathalie Ardjani & PPh Pasal 4 ayat 2 \\
\hline Erin Supriyanti & PPh Pasal 4 ayat 2 \\
\hline Regal Gautama & $\begin{array}{l}\text { PPh Pasal 23 (2006 - 2015), PPh Pasal } 4 \text { ayat } 2 \\
(2015-2018)\end{array}$ \\
\hline Andik Tri Sulistyono & Jasa manajemen, PPh Pasal 23 \\
\hline Hidayat Putra Jaya & Sewa tanah dan bangunan, PPh Pasal 4 ayat 2 \\
\hline Rika Hafidha Rahmasopha & Sewa tanah dan bangunan, PPh Pasal 4 ayat 2 \\
\hline David Hamzah Damian & PPh Pasal 4 ayat 1 \\
\hline Arief Sultony & Sewa tanah dan bangunan, PPh Pasal 4 ayat 2 \\
\hline Maulia Ghita & $\begin{array}{l}\text { PPh Pasal 23 atau PPh Pasal 4 ayat 2, tergantung } \\
\text { kontrak }\end{array}$ \\
\hline Ety Rahmawati & Sewa tanah dan bangunan, PPh Pasal 4 ayat 2 \\
\hline
\end{tabular}


dan jasa tersebut dapat dikenakan PPh Pasal 23.

Berdasarkan hasil wawancara, pendapat atas pengenaan pajak penghasilan atas jasa sewa kantor virtual dijelaskan pada Tabel 1.

Oleh karena itu, penulis menyimpulkan bahwa terdapat perbedaan perlakuan pengenaan pajak penghasilan antara penyedia jasa sewa kantor virtual satu dengan yang lain baik yang dikenakan PPh Pasal 4(2), PPh Pasal 23 ataupun Pasal 4 ayat 1 UU PPh.

\subsection{Perlakuan Pembebanan Biaya atas Layanan Pendukung Kantor}

Bagi penyedia jasa sewa kantor virtual, pendapatan diperoleh dari perjanjian sewamenyewa dengan pengguna jasa sewa kantor virtual. Dalam konteks jasa sewa kantor virtual, biaya yang dikeluarkan berhubungan dengan pengorbanan penyedia jasa sewa kantor virtual untuk mempertahankan kelangsungan kegiatan usaha dan mendapatkan perjanjian sewamenyewa dengan pengguna jasa sewa kantor virtual. Biaya tersebut dapat berupa biaya administrasi, biaya perizinan, biaya pemasaran, biaya keuangan, dan sebagainya.

Seperti yang telah dijelaskan sebelumnya, kantor virtual menurut PMK147/PMK.03/2017 adalah kantor yang memiliki ruangan fisik dan dilengkapi dengan layanan pendukung kantor. Layanan pendukung kantor tersebut merupakan fasilitas yang disediakan penyedia jasa sewa kantor virtual yang bertujuan mendukung penggunaan kantor virtual. Layanan pendukung kantor dapat diartikan sebagai pengorbanan yang dilakukan untuk memperoleh manfaat berupa pendapatan dari perjanjian sewamenyewa dengan pengguna jasa sewa kantor virtual.

Penyedia jasa sewa kantor virtual pada umumnya tidak hanya memperoleh pendapatan dari perjanjian sewa-menyewa dengan pengguna jasa sewa kantor virtual tetapi juga menyewakan serviced office. Serviced office ialah jasa sewa ruangan di suatu gedung dimana pengguna jasa memiliki hak eksklusivitas terhadap ruangan tersebut. Dengan demikian, penghasilan yang diterima atas jasa sewa serviced office merupakan sewa tanah dan bangunan yang dikenakan PPh Pasal 4 ayat 2. Selain itu, definisi kantor virtual menurut penyedia jasa sewa kantor virtual adalah sewa alamat bisnis yang diberikan beberapa fasilitas. Praktik pengenaan pajak penghasilan atas jasa sewa kantor virtual adalah PPh Pasal 4 ayat 2. Oleh karena itu, dapat disimpulkan bahwa penyedia jasa sewa kantor virtual menerima penghasilan yang dikenakan pajak penghasilan final.

Atas penghasilan berupa jasa sewa serviced office dan jasa sewa kantor virtual tersebut tidak diperhitungkan lagi di SPT Tahunan dengan penghasilan lain yang dikenakan pajak penghasilan tidak final untuk dikenakan tarif sesuai dengan Pasal 17 UU PPh. Berdasarkan Pasal 13 Peraturan Pemerintah (PP) Nomor 94 Tahun 2010 tentang Penghitungan Penghasilan Kena Pajak dan Pelunasan Pajak Penghasilan 
dalam Tahun Berjalan sebagaimana telah diubah terakhir dengan PP Nomor 9 Tahun 2021 tentang Perlakuan Perpajakan Untuk Mendukung Kemudahan Berusaha, biaya atas layanan pendukung kantor yang dikeluarkan oleh penyedia jasa sewa kantor virtual tidak bisa menjadi pengurang dalam menghitung Penghasilan Kena Pajak.

Bagi yang berpandangan bahwa pengenaan pajak penghasilan atas jasa sewa kantor virtual merupakan bagian dari jasa manajemen sehingga dikenakan PPh Pasal 23, penyedia jasa sewa kantor virtual dalam kondisi ini menerima penghasilan yang bersifat final dan tidak final. Biaya atas layanan pendukung kantor yang telah dijelaskan sebelumnya merupakan biaya untuk mendapatkan, menagih, dan memelihara penghasilan dari sewamenyewa serviced office yang dikenakan pajak penghasilan final dan kantor virtual yang dikenakan pajak penghasilan tidak final. Biaya ini disebut sebagai biaya bersama (joint cost). Biaya tersebut terkadang sulit untuk dipisahkan. Biaya atas layanan pendukung kantor yang dikeluarkan oleh penyedia jasa sewa kantor virtual bisa menjadi pengurang dalam menghitung Penghasilan Kena Pajak dengan cara dialokasikan secara proporsional. Namun konsekuensinya adalah penyedia jasa sewa kantor virtual harus menyelenggarakan pembukuan secara terpisah.

\section{KESIMPULAN}

Atas analisis aspek perpajakan atas jasa sewa kantor virtual, dapat disimpulkan bahwa terdapat perbedaan definisi kantor virtual antara WP dengan DJP. Kantor virtual bagi DJP adalah kantor yang memiliki ruangan fisik sedangkan bagi WP adalah sewa alamat bisnis yang diberikan fasilitas, salah satunya adalah ruangan rapat. Namun PMK-147/PMK.03/2017 memberikan toleransi atas praktik kantor virtual yang terjadi sehingga ruangan rapat yang dipakai bersama dapat dianggap sebagai ruangan fisik. Dengan demikian, definisi kantor virtual yang dapat disepakati WP dan DJP adalah kantor yang menyediakan ruangan fisik.

Objek atas jasa sewa kantor virtual adalah alamat kegiatan usaha. Pada praktiknya terdapat perbedaan pengenaan pajak penghasilan atas jasa sewa kantor virtual. Jasa sewa kantor virtual ada yang dikenakan PPh Pasal 4 ayat 2, namun jasa sewa kantor virtual juga dapat diartikan sebagai bagian dari jasa manajemen sehingga dikenakan PPh Pasal 23. Kemudian penghasilan atas jasa sewa kantor virtual ada yang dikenakan tarif PPh Badan karena tidak memenuhi definisi jasa manajemen dan tidak termasuk dalam positive list PMK141/PMK.03/2015.

Dalam hal kondisi kantor virtual dikenakan pajak penghasilan final, biaya atas layanan pendukung kantor tidak dapat menjadi pengurang Penghasilan Kena Pajak. Kemudian dalam kondisi kantor virtual dikenakan pajak penghasilan tidak final, biaya atas layanan pendukung kantor dapat menjadi pengurang Penghasilan Kena Pajak. 
Oleh karena itu, dari segi regulasi, aspek perpajakan terkait jasa sewa kantor virtual perlu diperjelas agar tercipta kepastian hukum.

\section{IMPLIKASI DAN KETERBATASAN}

Penelitian ini memiliki keterbatasan mengenai aspek perpajakan atas jasa sewa kantor virtual atas WP Badan yang memiliki kantor virtual dan berkedudukan hukum di Indonesia. Untuk memperoleh analisis yang mendalam, penelitian ini dibatasi pada analisis pengenaan pajak terhadap penghasilan atas jasa sewa kantor virtual dan perlakuan biaya atas layanan pendukung kantor yang dikeluarkan oleh penyedia jasa kantor virtual. Untuk penelitian selanjutnya, penulis menyarankan agar dilakukan penelitian lebih lanjut jasa sewa kantor virtual bila diterapkan pada kantor pemerintahan, observasi mendalam secara langsung terhadap laporan keuangan penyedia jasa sewa kantor virtual, dan pelaksanaan kantor virtual yang terindikasi tindak pidana perpajakan.

\section{DAFTAR PUSTAKA}

[1] Ariani, D. W. (2009). Manajemen operasi jasa. Yogyakarta: Graha IImu.

[2] Crosswell, John W. 2016, Research Design: Pendekatan Metode Kualitatif, Kuantitatif, dan Campuran. Edisi Ke-4, Yogyakarta: Pustaka Pelajar.

[3] Ciptadi, M. A. (2014). Tinjauan yuridis mengenai perjanjian sewa-menyewa virtual office dan dampak penggunaan alamat virtual office sebagai domisili pada perjanjian [unpublished thesis]. Universitas Indonesia.

[4] Habib, L., \& Cornford, T. (2014). The virtual office and family life. London: Department of Information Systems, London School of Economic, 1.

[5] Internet World Stats. (2018). Internet 2018 usage in Asia. Retrieved March 18, 2018, from https://www.internetworldstats.com/stats3.htm

[6] Keputusan Direktur Jenderal Pajak Nomor KEP321/PJ/2012 tentang Perubahan atas Keputusan Direktur Jenderal Pajak Nomor KEP-233/PJ/2012 tentang Klasifikasi Lapangan Usaha Wajib Pajak. Jakarta.

[7] Kitab Undang-Undang Hukum Perdata (Burgerlijk Wetboek). Diterjemahkan oleh Subekti dan R. Tjitrosudibio. (2009). Jakarta: Pradya Paramita

[8] McLeod, R., \& Schell, G. P. (2008). Management information systems (10th ed.). Prentice Hall: Pearson Education.

[9] Mulyadi. (2010). Akuntansi biaya. Yogyakarta: Sekolah Tinggi Ilmu Manajemen YKPN.

[10] Peraturan Menteri Keuangan Nomor 146/PMK.03/2012 tentang Tata Cara Verifikasi. Berita Negara Tahun 2012 Nomor 93. Jakarta.

[11] Peraturan Menteri Keuangan Nomor 141/PMK.03/2015 tentang Jenis Jasa Lain Sebagaimana Dimaksud Dalam Pasal 23 Ayat (1) Huruf C Angka 2 Undang-Undang Nomor 7 Tahun 1983 Tentang Pajak Penghasilan Sebagaimana Telah Beberapa Kali Diubah Terakhir Dengan Undang-Undang Nomor 36 Tahun 2008. Berita Negara Tahun 2015 Nomor 1086. Jakarta.

26

[12] Peraturan Menteri Keuangan Nomor 182/PMK.03/2015 tentang Tata Cara Pendaftaran Nomor Pokok Wajib Pajak, Pengukuhan Pengusaha Kena Pajak, Penghapusan Nomor Pokok Wajib Pajak, dan Pencabutan Pengukuhan Pengusaha Kena Pajak. Berita Negara Tahun 2015 Nomor 1466. Jakarta.

[13] Peraturan Menteri Keuangan Nomor 147/PMK.03/2017 tentang Tata Cara 
Pendaftaran Wajib Pajak dan Penghapusan Nomor Pokok Wajib Pajak serta Pengukuhan dan Pencabutan Pengukuhan Pengusaha Kena Pajak. Berita Negara Tahun 2017 Nomor 1516. Jakarta.

[14] Peraturan Pemerintah Nomor 94 Tahun 2010 tentang Penghitungan Penghasilan Kena Pajak dan Pelunasan Pajak Penghasilan dalam Tahun Berjalan. Lembaran Negara Tahun 2010 Nomor 161. Jakarta.

[15] Peraturan Pemerintah Nomor 45 Tahun 2019 tentang Perubahan atas Peraturan Pemerintah Nomor 94 Tahun 2010 tentang Penghitungan Penghasilan Kena Pajak dan Pelunasan Pajak Penghasilan dalam Tahun Berjalan. Lembaran Negara Tahun 2019 Nomor 119. Jakarta.

[16] Peraturan Pemerintah Nomor 9 Tahun 2021 tentang Perlakuan Perpajakan Untuk Mendukung Kemudahan Berusaha. Lembaran Negara Tahun 2021 Nomor 19. Jakarta.

[17] Sugiyono. (2016). Metode penelitian bisnis (pendekatan kuantitatif, kualitatif, dan R\&D). Bandung: Alfabeta.

[18] Undang-Undang Nomor 36 Tahun 2008 tentang Perubahan Keempat Atas UndangUndang Nomor 7 Tahun 1983 tentang Pajak Penghasilan. Lembaran Negara Tahun 2008 Nomor 133. Jakarta.

[19] Utami, S. S. (2010). Pengaruh teknologi informasi dalam perkembangan bisnis. Jurnal Akuntansi dan Sistem Teknologi Informasi,8(1), 61-67 


\section{LAMPIRAN}

Tabel 1 Daftar Narasumber

Sumber: Data diolah

\begin{tabular}{|c|c|c|c|}
\hline No. & Nama & Instansi/Lembaga & Peran \\
\hline 1. & $\begin{array}{l}\text { Andik Tri } \\
\text { Sulistyono }\end{array}$ & $\begin{array}{l}\text { Kepala Seksi Peraturan Ketentuan Umum dan Tata Cara } \\
\text { Perpajakan Direktorat Peraturan Perpajakan I }\end{array}$ & Regulator \\
\hline 2. & $\begin{array}{l}\text { Dony Katra } \\
\text { Lubis }\end{array}$ & $\begin{array}{l}\text { Pelaksana Seksi Peraturan Penagihan Pajak dengan Surat } \\
\text { Paksa Direktorat Peraturan Perpajakan I }\end{array}$ & Regulator \\
\hline 3. & $\begin{array}{l}\text { Ety } \\
\text { Rahmawati }\end{array}$ & $\begin{array}{l}\text { Pelaksana Seksi Peraturan Pemotongan dan Pemungutan } \\
\text { PPh II Direktorat Peraturan Perpajakan II }\end{array}$ & Regulator \\
\hline 4. & $\begin{array}{l}\text { Hidayat } \\
\text { Putra Jaya }\end{array}$ & $\begin{array}{l}\text { Kepala Seksi Pengawasan dan Konsultasi I KPP Pratama } \\
\text { Jakarta Tebet }\end{array}$ & Praktisi - DJP \\
\hline 5. & $\begin{array}{l}\text { Rika Hafidha } \\
\text { Rahmasopha }\end{array}$ & $\begin{array}{l}\text { Account Representative Seksi Ekstensifikasi dan Penyuluhan } \\
\text { KPP Pratama Jakarta Tebet }\end{array}$ & Praktisi - DJP \\
\hline 6. & $\begin{array}{l}\text { David } \\
\text { Hamzah } \\
\text { Damian }\end{array}$ & Partner of Tax Compliance and Litigation Services & Akademisi \\
\hline 7. & Arief Sultony & Widyaiswara Pusdiklat Pajak & Akademisi \\
\hline 8. & Maulia Ghita & Widyaiswara Pusdiklat Pajak & Akademisi \\
\hline 9. & $\begin{array}{l}\text { Nathalie } \\
\text { Ardjani }\end{array}$ & $\begin{array}{l}\text { Tenant Relations Manager - Penyedia Jasa Sewa Kantor } \\
\text { Virtual }\end{array}$ & Praktisi \\
\hline 10. & $\begin{array}{l}\text { Erin } \\
\text { Supriyanti }\end{array}$ & Center Manager- Penyedia Jasa Sewa Kantor Virtual & Praktisi \\
\hline 11. & $\begin{array}{l}\text { Regal } \\
\text { Gautama }\end{array}$ & Community Manager - Penyedia Jasa Sewa Kantor Virtual & Praktisi \\
\hline
\end{tabular}

